\title{
Raymond de Vieussens (1641-1715): connoisseur of cardiologic anatomy and pathological forms thereof
}

\author{
Sanjib Kumar Ghosh, Ananya Priya, Ravi Kant Narayan \\ Department of Anatomy, All India Institute of Medical Sciences, Patna, India
}

\begin{abstract}
Raymond de Vieussens was an exemplary anatomist who made seminal contributions in the field of cardiology. During initial part of his academic career, he adopted human dissection based experiments as medium of his research. This was in accordance with prevailing trend among anatomists during 17th century. He discovered the presence of tiny venous tributaries communicating between cardiac veins and chambers of heart (ducti carnosi/venae cordis minimae). He reported the existence of a collateral circulatory pathway between right and left coronary arterial systems (Vieussens arterial ring). He was the first to note the valve at the junction of great cardiac vein and coronary sinus (valve of Vieussens) and the prominent oval margin of the fossa ovalis (Vieussens Annulus). All his findings were associated with considerable clinical significance as evidenced in literature that followed. Vieussens accurately demonstrated the three-layered orientation of myocardium and gave a precise description of coronary arteries and their branches. At the onset of 18th century, buoyed by royal patronage from King Louis XIV of France, the second half of Vieussens illustrious career was defined by pathologic anatomy (autopsy based) and anatomo clinical correlations. This was a new trend initiated by Vieussens in anatomical research and was later adopted as a signature method by anatomists of 18th century. As a true connoisseur of cardiologic anatomy, Vieussens accurately charted the anatomo clinical correlations of cardiac tamponade, mitral stenosis and aortic regurgitation. His contributions were pivotal elements in metamorphosis of cardiology as a robust discipline of medicine in modern times.
\end{abstract}

Key words: Vieussens, Cardiology, Ducti carnosi, Vieussens ring, Mitral stenosis

Received May 25, 2021; Revised June 28, 2021; Accepted July 13, 2021

\section{Introduction}

Raymond de Vieussens (1641-1715) was a French anatomist (Fig. 1) who made cardinal contributions in the field of cardiology [1]. He was a pioneer figure of cardiologic anatomy and torch bearer of two classic trends that defined anatomical research in 17th and 18th centuries. He diligently

Corresponding author:

Sanjib Kumar Ghosh (iD

Department of Anatomy, All India Institute of Medical Sciences, Patna 801507, Bihar, India

E-mail: drsanjib79@gmail.com followed the human dissection based experimental methods during the late 17th century and heralded the trend of pathologic anatomy (autopsy based research) which became the signature model of 18th century anatomists [2]. His work is seminal in the field of cardiology and constitutes an important transitional phenomenon in terms of scientific outlook of research methods across centuries [3]. His discoveries and observations contributed significantly towards the advancement of cardiology and paved the way for its emergence as a sovereign discipline within the realm of medical science [4]. It was hypothesized that the seminal contributions of this exemplary anatomist need to be revisited as they constitute significant landmarks in the process involving the metamorphosis of cardiology into its present form as we are familiar

\section{Copyright (c) 2021. Anatomy \& Cell Biology}

This is an Open Access article distributed under the terms of the Creative Commons Attribution Non-Commercial License (http://creativecommons.org/licenses/by-nc/4.0/) which permits unrestricted non-commercial use, distribution, and reproduction in any medium, provided the original work is properly cited. 


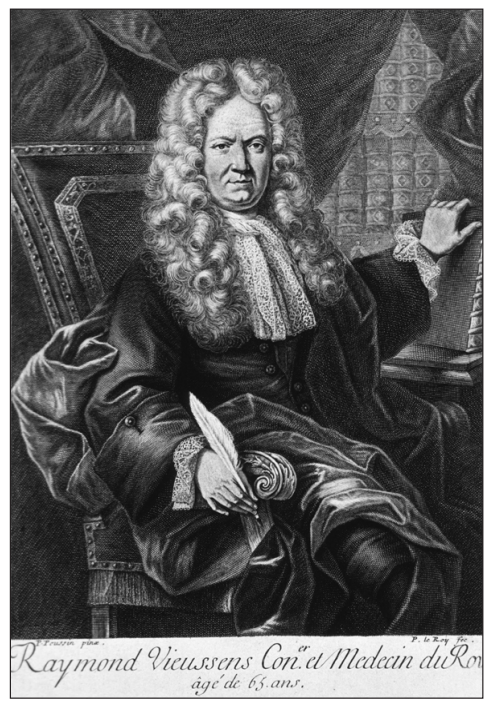

Fig. 1. A portrait of Raymond de Vieussens. Image in public domain and free from copyright issues. Source of image: Wikimedia Commons.

with in modern times. Hence the present study was conducted to chronicle the life and achievements of this visionary anatomist.

\section{Methods}

An extensive literature search was undertaken for this study and indexed databases such as MEDLINE, PubMed, Scopus, EMBASE, CINAHL, Google Scholar as well as popular search platforms such as Wikipedia and standard Google search engine were referred to relevant published materials. The following terms were used during literature search: "Raymond de Vieussens," "Vieussens," "Raymond Vieussens biography," "Vieussens and cardiology," "Vieussens and cardiovascular system," "Vieussens and anatomy," "Vieussens and heart," "cardiology in 17th century," "cardiology in 18th century," "pathologic anatomy," and "Vieussens eponyms." Published texts of Vieussens and their translations in English were consulted from online libraries while conducting the present study and wherever applicable have been appropriately referenced. The images used in the text were procured from the internet and it was ensured that all figures included in this study are in public domain i.e. free from copyright issues. Nevertheless, the source of these images have been duly acknowledged in their respective legends.

\section{Onset of Career in Medicine at Montpellier}

Raymond de Vieussens was born in 1641 in the commune of Le Vigan situated in Rouergue province of Southern France [1]. Not much is known about his early days and there is even confusion regarding his actual year of birth as few literature mentions it as 1635 [4]. His father Francois was a high ranking official in the French Army and Vieussens went on to become a first generation physician. During early part of his career Vieussens registered himself as a student of philosophy in Rodez, a small city on Southern France [5]. As destiny would unfold, Vieussens eventually moved to Montpellier and began his eventful journey in medicine and anatomical research in the famed University which is eponymous with the city [6]. Vieussens's career as an avid researcher in anatomy was shaped during his training as a medical graduate from the prestigious University of Montpellier. It may be mentioned here that the University is among the earliest ones established in Europe (founded in 1220) [7]. It witnessed the first human dissection being conducted by French anatomist and surgeon Henri de Mondeville in 1315. Although the exercise was not legitimized by religious authorities, nevertheless it was a bold step towards breaking the shackles that hindered academic advances in medicine for 1700 years. Luminaries in anatomical sciences like Jacobus Sylvius (15th century), Andreas Vesalius (16th century) and Jean Pecquet (17th century) were associated with this illustrious institution [8]. Therefore, it was no surprize that Vieussens embraced anatomical research as his career path. In accordance with the trend prevailing among anatomists during 17th century, Vieussens also adopted experimental models based on human dissection as his medium of research activities $[9,10]$. This aspect of Vieussens's career was influenced by the academic environment in his alma mater as human dissection was routinely practised for teaching anatomy in Montpellier. More significantly, Vieussens's journey to explore the unfound anatomical attributes received a major boost from the availability of large number of human cadavers in Montpellier, which was subsequently acknowledged in his communication with peers [11].

\section{Early Venture in Neuroanatomy}

As a medical graduate, Vieussens joined in the post of a physician in the Saint-Eloi Hospital in Montpellier in 1670. In addition to his normal duties, Vieussens devoted himself 
to anatomical research [3]. Like many of his contemporaries, Vieussens was remarkably influenced by the works of British anatomist Thomas Willis (1621-1675), whose seminal works in the domain of brain and nervous system were published around this time. Willis had documented his observations in Cerebri Anatome (published in 1664) and Pathologiae Cerebri et nervosa (published in 1667) [12]. Vieussens tirelessly worked on unravelling the anatomical details related to central and peripheral nervous system for the next ten years. The fact that he dissected 500 human cadavers during this period is a testimony of his hard work and dedication to the advancement of science [11]. The culmination of his humongous efforts was the publication of a compilation of his findings as Neurographia Universalis in 1685. Vieussens gave valuable insights on the structure and function of spinal cord, visual pathway and finer structural details of brainstem components [13]. Subsequent to the publication of his work, Vieussens received recognition in France (he was inducted as a member of the Academy of Sciences in Paris) as well as in Europe as such (he was honoured with the fellowship of Royal Society of London) [11]. However, the turning point in his academic career came in 1688, when his work received appreciation from the royal family of France. King Louis XIV himself was a great admirer of Vieussens and granted him an annual pension of 1,000 livres [1]. It is needless to mention that this economic support further strengthened his resolve to explore the human anatomical details through experiment based observations. His already glittering academic career continued to flourish even further under the royal patronage.

\section{Discoveries in Cardiologic Anatomy}

In the following years, Vieussens continued to work in Saint-Eloi Hospital and began his journey in the domain of cardiologic anatomy [3]. His inclination towards the anatomy of heart was possibly fuelled by pivotal observations documented by English physician William Harvey (1578-1657) regarding the anatomy of circulation and heart during the first half of 17 th century [14]. Vieussens made a number of fascinating observations (Fig. 2) which he eventually published in 1705 as Novum vasorum corporis humani systema [15]. He was the first to describe the presence of tiny venous tributaries communicating between cardiac veins and chambers of heart [16]. As part of his experimental design, he ligated the superior and inferior vena cava as well as pulmonary veins. This was followed by injecting saffron dye into the coronary arteries. The dye followed its normal anatomical course and entered the coronary capillary network (located in myocardium) and then entered the cardiac veins and eventually into coronary sinus. Surprisingly, a small amount of dye was also observed in the ventricles of heart. Vieussens thus unveiled the minute cardiac venous tributaries and introduced the nomenclature 'ducti carnosi' [15]. However, a couple of years later, German anatomist Adam Thebesius (1686-1732) provided a more detailed account on the anatomy of these veins and hence they are eponymous as 'Thebesian veins' in present times [17]. The more accepted nomenclature is however 'venae cordis minimae,' which is used in contemporary texts [18].

Vieussens reported the existence of a unique arterial pathway linking the conus branch of right coronary artery with the conus branch of left anterior descending coronary artery (branch of left coronary artery). He described the structural anatomy of this arterial pathway in the form of a ring. It has become eponymous as Vieussens Arterial Ring (VAR) in the field of cardiology. Vieussens described this anatomical entity in details in his text Nouvelles Decouvertes sur le coeur which was published in 1706 [19]. Later on it was observed

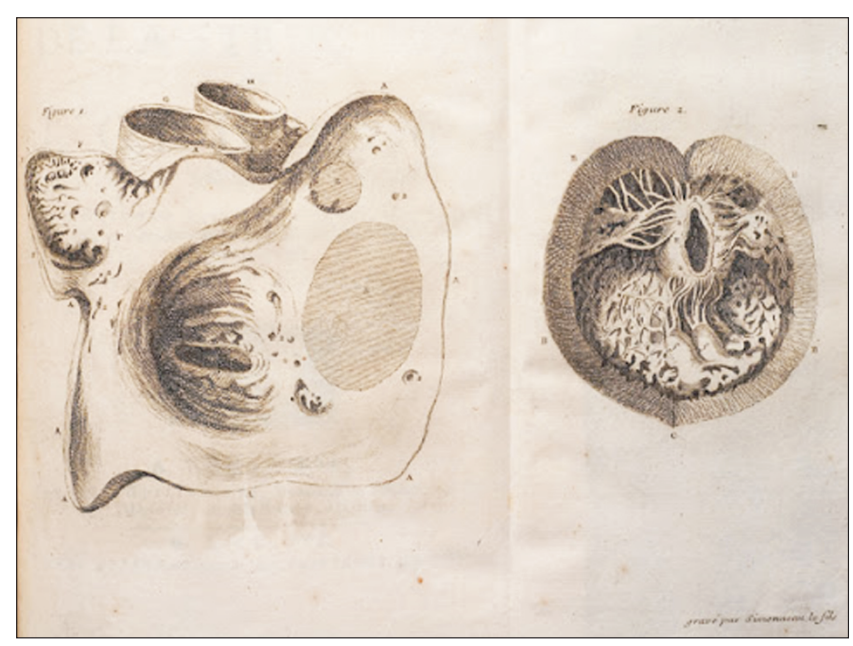

Fig. 2. Illustrations showing the structure of tricuspid valve as observed from a superior view. The valve is shown after opening the walls of right atrium and also after opening the walls of right ventricle. In the right ventricle the tricuspid valve is shown along with the three papillary muscles which are attached to the valve cusps via chordae tendinae. The illustration was prepared by Lason (artist) in Montpellier at the time of dissection by Vieussens. Later the drawings were converted to engravings by Simmoneau (engraver) in Paris. Image in public domain and free from copyright issues. Source of image: Wikimedia Commons. 
that VAR is present in $48 \%$ individuals and assumes significance from clinical perspective as it acts as a collateral circulatory pathway between the right and left coronary arterial system thus serving as a protective measure in case of coronary artery occlusive disease [20].

Vieussens also discovered the presence of a valve at the junction of great cardiac vein and coronary sinus [19]. This anatomical entity is known as the valve of great cardiac vein and is often referred to as 'valve of Vieussens' in contemporary literature. This anatomical structure holds significance in the field of clinical cardiology as depending on its morphology it may potentially cause obstruction during cardiac catheterization procedures [21]. Vieussens was the first to note the prominent oval margin of the fossa ovalis (limbus fossa ovalis) in the adult heart [19]. He identified that this anatomical structure develops from a different embryological component (septum secundum) as compared to the fossa ovalis (septum primum). Limbus fossa ovalis or annulus fossa ovalis is also referred to as 'Vieussens Annulus' [22]. The exemplary success of Vieussens in terms of unveiling the hitherto unknown details of cardiologic anatomy made him immensely popular as an anatomist across Europe [1]. Unsurprisingly, his achievements got the attention from his royal patrons and his annual pension was enhanced to 3,000 livres in 1707. As a mark of honour, Vieussens was appointed as a Conseiller (advisor) of state by King Louis XIV in the

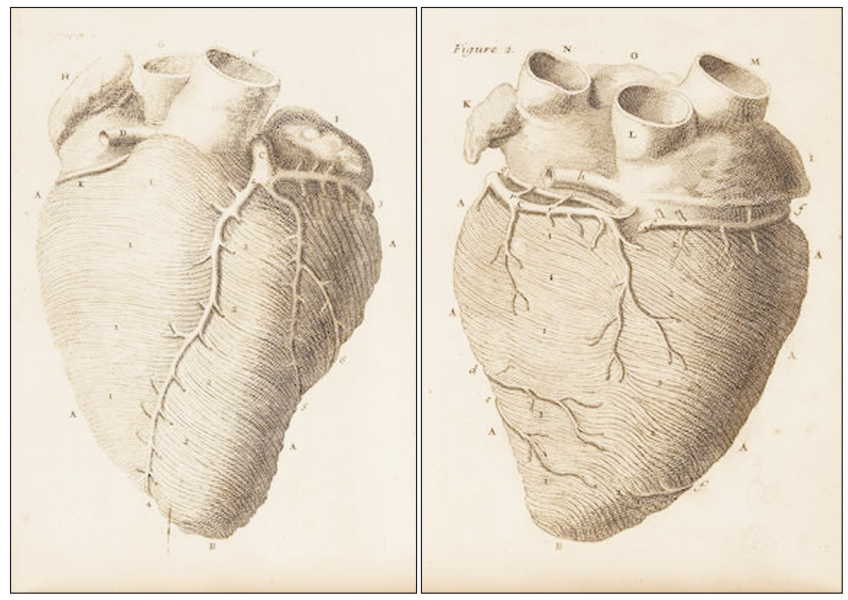

Fig. 3. Illustrations showing the middle layer of myocardium which has fibres in horizontal direction in the right ventricle and oblique direction in the left ventricle. Remarkably the distribution of the coronary arteries have been kept intact on the surface of the heart by Lason (artist) who prepared the drawing for Vieussens. Image in public domain and free from copyright issues. Source of image: Wikimedia Commons. same year [11]

Invigorated by the recognition as well as adulation of his work, Vieussens continued with his experiments in cardiologic anatomy and the mystique associated with this vital organ of the human body was gradually unmasked before him. A considerable number of his findings were published less than one year before his death in 1715 as Traite Nouveau de la structure et de la Cause de Mouvement Naturel du coeur [23]. He described in detail the organization of myocardial fibres in the right and left ventricles of heart. He demonstrated that the myocardium is arranged in three layers: superficial, middle and deep. The muscle fibres are arranged vertically in the superficial and deep layers. The middle layer (more prominent in left ventricle) has horizontal fibres in the right ventricle and oblique fibres in the left ventricle (Fig. 3) [23]. His findings were later validated through advanced techniques in contemporary period albeit with modification of few finer details [24].

Vieussens was the first anatomist to give a precise description of the location and the course of coronary arteries, their branches and the coronary sinus $[23,25]$. They were demonstrated by means of fine illustrations in his published works (Fig. 4). Vieussens described the pericardium of the heart as a bilayered sac like structure covering the organ [23]. It may be mentioned here that the gross anatomical details of pericardium were actually described by Vesalius in the 16th

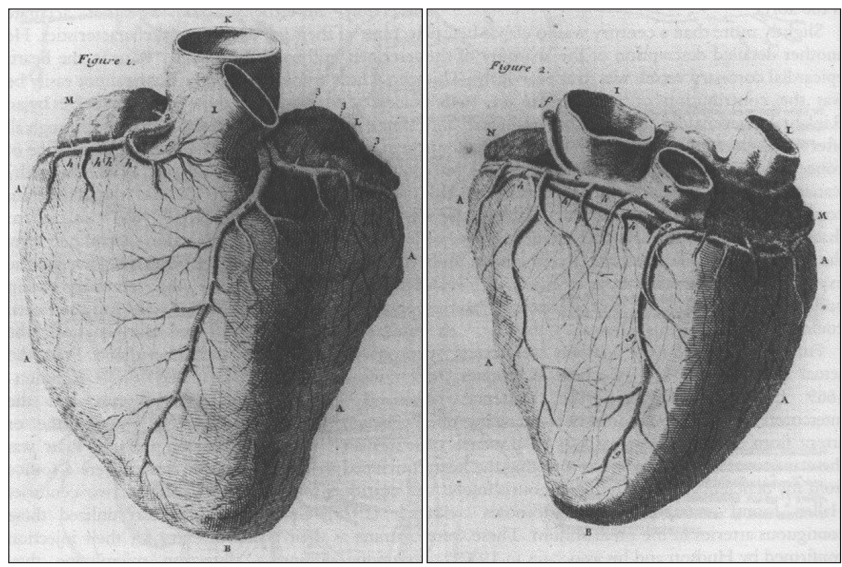

Fig. 4. Illustrations showing distribution of coronary arteries on the surface of heart. On the anterior surface of heart course of right coronary artery and those of left anterior descending artery as well as circumflex artery (both branches of left coronary artery) are demonstrated. On the inferior surface course of posterior descending artery (branch of right coronary artery) and circumflex artery (branch of left coronary artery) are depicted. Image in public domain and free from copyright issues. Source of image: Wikimedia Commons. 
century itself. However, Vieussens accurately charted the clinical scenario associated with significant accumulation of fluid between two layers of pericardium. He hypothesized that the pericardial fluid compresses the heart whereby the chambers cannot dilate to their full capacity thus generating a feeble pulse. His clinical correlation of the anatomo-pathological condition had pin point precision based on which he could accurately diagnose a case of cardiac tamponade where the face of a patient became darker as his pulse became faster but weaker [26].

\section{Trendsetter in Pathologic Anatomy within the Realm of Cardiology}

In addition to descriptions of normal anatomy of the heart, Vieussens initiated a new trend of detailing its pathologic anatomy. Vieussens used to correlate the findings in the cardiac tissue during autopsy of diseased patients with clinical manifestations when the same patient was alive [27]. Using this method which was unique in itself and different from the dissection based experiments prevalent during 17th century, Vieussens charted the anatomo clinical correlation of a classical case of mitral stenosis in his text Traite Nouveau (published in 1715) [23]. The observation was made by Vieussens in 1705, when a young man aged 30 was admitted at Saint-Eloi Hospital. The patient lied in a bed with his head propped up, having great difficulty in breathing with his heart beating with violent palpitation, his pulse feeble with eyes sunken and lips dark in appearance. Vieussens concluded a poor prognosis which was validated a week later vas the patient died. Vieussens himself conducted the autopsy and correlated his observations (pathology) with logical sequence of events involving the structures of the heart (anatomy). The principal observations were listed as chest cavity filled with yellowish serous fluid, both the lungs abnormally large in size and soft in consistency, heart became enlarged with dilated pulmonary veins. On opening the heart he noted that the right ventricle and right atrium were inordinately enlarged (Fig. 5). He also observed that the substance of mitral valve became bone like in appearance with consequent narrowing of the lumen into the left ventricle. He unerringly identified the mitral valve as the seat of the pathological condition (mitral stenosis). In a sequential manner he traced that with impairment of circulation the pulmonary veins were dilated eventually leading to stasis of blood in pulmonary vessels resulting in the enlargement of lungs, difficulty in breathing (impaired exchange of gases at alveolar level) and oozing out of serous component of blood in the chest cavity. Vieussens also concluded that the accumulated blood in the pulmonary circulation led to violent contraction of the right ventricle (visible palpation and enlargement in size). Also, as left ventricle was pumping very little blood into circulation, the pulse was weak and peripheries exhibited dark colour [23, 28].

Vieussens also presented the anatomo clinical correlation in a case of severe aortic insufficiency (aortic regurgitation) with remarkable precision [23]. The patient was a young male who presented with a pulse that was violent and whose nature was unknown to Vieussens till then. Vieussens however categorized the condition as catastrophic and associated with a serious pathologic condition of the heart. During autopsy Vieussens observed a markedly dilated left ventricle and the semilunar aortic valves were unusually stretched. He concluded failure of the aortic valve as root cause of the pathologic condition, whereby during each ventricular contraction a portion of the blood that was just pumped into the aorta was sent back to the left ventricle. This event led to the generation of the powerful and anomalous pulse evident at the peripheral arteries $[4,23]$. This type of peripheral pulsation is referred to as the 'Watson's water hammer pulse' or 'Corrigan's pulse' or 'collapsing pulse' in contemporary

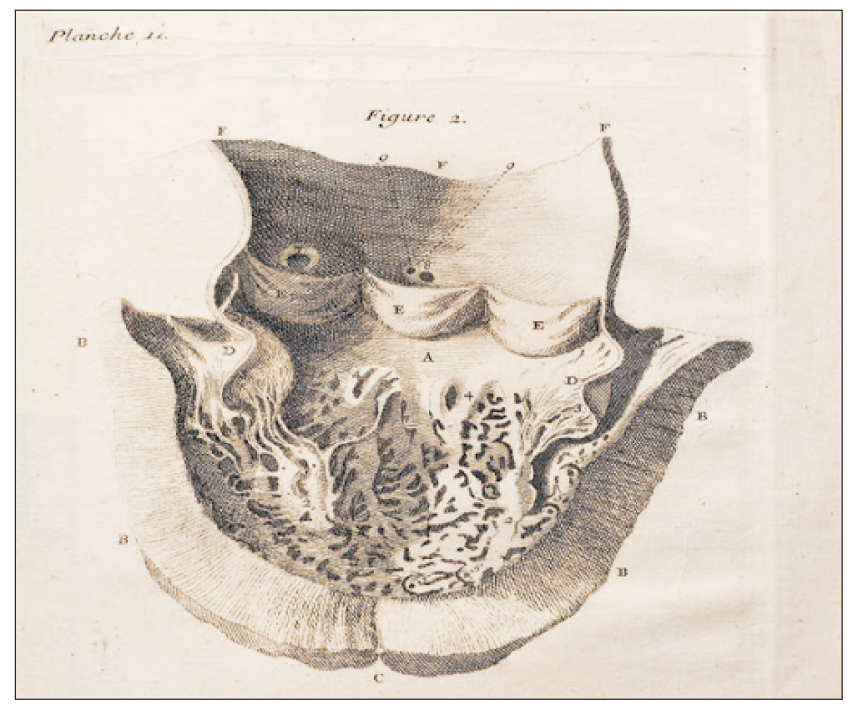

Fig. 5. Illustration showing the interior of right ventricle in a case of mitral stenosis. The internal features of the right ventricle are abnormally enlarged and its walls (myocardium) are inordinately thickened. The anatomical features observed in right ventricle of the heart are a consequence of mitral stenosis which is the pathological condition involving the heart. Image in public domain and free from copyright issues. Source of image: Wikimedia Commons. 
literature. The pulse is described as bounding and forceful, rapidly increasing followed by subsequent collapsing and is characteristic of aortic regurgitation [29]. The visionary efforts of Vieussens revolutionized anatomical studies during the 18th century as the concept of pathologic anatomy gained immense popularity in the academic domain.

\section{Pivotal Anatomical Figure at the Transition of 17th and 18th Century}

Vieussens role as researcher in anatomy was pivotal and his contributions were critical in shaping the evolutionary pathway of cardiology as a prominent discipline in medical sciences [30-32]. During the initial part of his glowing academic career, particularly with reference to his first ten years in Saint-Eloi Hospital, his research methodology was based on human dissection based experiments [11]. Here he is seen as an anatomist following the footsteps of his luminary predecessors from 17th century like Harvey, Pecquet, Bartholin, and Malpighi [33]. However, in the second half of his career, particularly after receiving royal patronage, he was more inclined to autopsy based findings for his academic pursuits [4]. Maybe this change in perception was a result of his booming confidence, social prestige and also the economic security that comes collaterally with royal patronage. Nevertheless, this proved to be boon not only for cardiologic anatomy but anatomical sciences as such. Pathologic anatomy (autopsy based study of anatomy) emerged as a popular trend and later on it was pioneered by noted anatomists of 18th century like Giovanni Battista Morgagni, William Hunter and his brother John Hunter for significant discoveries in relation to pathologic anatomy of the heart and its valves as well as those of blood vessels in the human body [34, 35]. Hence it may be opined that in the history of anatomy, Vieussens holds his position as a vital link between the scientific revolution of 17 th century and remarkable advances during 18 th century.

\section{Conclusion}

Raymond de Vieussens was an exemplary anatomist of his time and his impeccable experimental methods with subsequent observations thereof brought him to the forefront of cardiologic anatomy during early 18th century. His extensive volume of scientific works essentially comprises of an amalgamation of normal anatomical details and patho- logical deviations in anatomical structures. His discoveries were pivotal in the advancement of cardiology and triggered its eventual rise as a prominent medical discipline in modern times.

\section{ORCID}

Sanjib Kumar Ghosh:

https://orcid.org/0000-0002-7293-6735

Ananya Priya: https://orcid.org/0000-0003-2787-1052

Ravi Kant Narayan:

https://orcid.org/0000-0003-2510-6744

\section{Author Contributions}

Conceptualization: SKG. Data acquisition: SKG. Data analysis or interpretation: SKG, AP, RKN. Drafting of the manuscript: SKG, AP, RKN. Critical revision of the manuscript: SKG, AP, RKN. Approval of the final version of the manuscript: all authors.

\section{Conflicts of Interest}

No potential conflict of interest relevant to this article was reported.

\section{Acknowledgements}

The authors express heartfelt gratitude to all the residents and faculty members of the Department of Anatomy, All India Institute of Medical Sciences, Phulwari Sharif, Patna, India for their unconditional support throughout the study. We are grateful to the authorities of All India Institute of Medical Sciences, Phulwari Sharif, Patna, India for their kind cooperation during the course of this study.

\section{References}

1. Kellett CE. The life and work of Raymond de Vieussens. Ann Med Hist 1942;4:31-54.

2. Amalric P. [Birth of neuro-ophthalmology in Montpellier in the 17th century through the works of Raymond Vieussens and Guilhem Briggs]. Bull Soc Ophtalmol Fr 1983;83:83-8. French.

3. Podolsky E. Raymond Vieussens and the affairs of the heart. Med Womans J 1952;59:29-31 passim.

4. Loukas M, Clarke P, Tubbs RS, Kapos T. Raymond de Vieussens. Anat Sci Int 2007;82:233-6. 
5. Dulieu L. Raymond Vieussens. Monspel Hippocrates 1967;10:926.

6. Mounier-Kuhn P, Guerrier Y. Vieussens et l'anatomie de l'oreille [Vieussens and the anatomy of the ear]. Acta Otorhinolaryngol Belg 1982;36:1029-38. French.

7. Bonnel F, Lavabre-Bertrand T, Bonnel C. The teaching of anatomy in Montpellier University during VIII centuries (12202020). Surg Radiol Anat 2019;41:1119-28.

8. Ghosh SK. Human cadaveric dissection: a historical account from ancient Greece to the modern era. Anat Cell Biol 2015;48:153-69.

9. Ghosh SK, Kumar A. Marcello Malpighi (1628-1694): Pioneer of microscopic anatomy and exponent of the scientific revolution of the 17th Century. Eur J Anat 2018;22:433-9.

10. Ghosh SK, Sharma S, Biswas S, Chakraborty S. Adriaan van den Spiegel (1578-1625): anatomist, physician, and botanist. Clin Anat 2014;27:952-7.

11. Vergani F, Morris CM, Mitchell P, Duffau H. Raymond de Vieussens and his contribution to the study of white matter anatomy: historical vignette. J Neurosurg 2012;117:1070-5.

12. Ghosh SK, Narayan RK. Anatomy of nervous system and emergence of neuroscience: a chronological journey across centuries. Morphologie 2020;104:267-79.

13. Vieussens R. [Neurographia universalis]. Lyons: Apud Joannem Certe; 1685. p. 252. Latin.

14. Harvey W. [Exercitatio anatomica de motu cordis et sanguinis in animalibus]. Frankfurt: Fitzeri; 1628. p. 236. Latin.

15. Vieussens R. [Novum vasorum corporis humani systema]. Amsterdam: Apud Paulum Marret; 1705. p. 144. Latin.

16. Snodgrass BT. Vessels described by Thebesius and Pratt are distinct from those described by Vieussens and Wearn. Am J Cardiol 2012;110:160.

17. Mazurak M, Kusa J. Adam Christian Thebesius' channels into the human heart: the Thebesian veins and the Thebesian valve. Tex Heart Inst J 2019;46:175-8.

18. Standring S. Gray's anatomy: the anatomical basis of clinical practice. 42nd ed. London: Elsevier; 2020. 1606 p.

19. Vieussens R. [Nouvelles decouvertes sur le coeur]. Paris: Chez Laurent D’Houry; 1706. p. 43. French.

20. Doğan N, Dursun A, Özkan H. Vieussens' arterial ring: a rare coronary variant anatomy. Diagn Interv Radiol 2019;25:109-13.

21. Corcoran SJ, Lawrence C, McGuire MA. The valve of Vieus- sens: an important cause of difficulty in advancing catheters into the cardiac veins. J Cardiovasc Electrophysiol 1999;10:8048.

22. Caliot P, Bousquet V, Cabanie P, Midy D. The nerve loops crossing below the subclavian artery and their anatomical variations. Anat Clin 1984;6:209-13.

23. Vieussens R. [Traité nouveau de la structure et des causes du mouvement naturel du coeur]. Toulouse: Jean Guillemette; 1715. 102 p. French.

24. Pearlman ES, Weber KT, Janicki JS, Pietra GG, Fishman AP. Muscle fiber orientation and connective tissue content in the hypertrophied human heart. Lab Invest 1982;46:158-64.

25. Major RH. Raymond Vieussens and his treatise on the heart. Ann Med Hist 1932;4:147-54.

26. Spodick DH. Medical history of the pericardium. The hairy hearts of hoary heroes. Am J Cardiol 1970;26:447-54.

27. Buess H. Theophil Bonet (1620-1689) und die grundsätzliche Bedeutung seines Sepulchretum in der Geschichte der pathologischen Anatomie [Theophil Bonet and the significance of his Sepulchretum in the history of pathologic anatomy]. Gesnerus 1951;8:32-52. German.

28. Kellett CE. Raymond de Vieussens on mitral stenosis. Br Heart J 1959;21:440-4.

29. Suvarna JC. Watson's water hammer pulse. J Postgrad Med 2008;54:163-5.

30. Reichert P. A history of the development of cardiology as a medical specialty. Clin Cardiol 1978;1:5-15.

31. Ghosh SK, Raheja S, Tuli A. Obstructive Thebesian valve: anatomical study and implications for invasive cardiologic procedures. Anat Sci Int 2014;89:85-94.

32. Gumpangseth T, Lekawanvijit S, Mahakkanukrauh P. Histological assessment of the human heart valves and its relationship with age. Anat Cell Biol 2020;53:261-71.

33. Ghosh SK. Thomas Bartholin (1616-1680): Danish anatomist and his cardinal contributions towards the discovery of the lymphatic system. Eur J Anat 2017;21:261-8.

34. Ghosh SK. Giovanni Battista Morgagni (1682-1771): father of pathologic anatomy and pioneer of modern medicine. Anat Sci Int 2017;92:305-12.

35. Chitwood WR Jr. John and William Hunter on aneurysms. Arch Surg 1977;112:829-36. 